\title{
AN INVESTIGATION INTO THE APPLICABILITY OF NATURAL LOAD VARIATION SCHEME TO THE MEASUREMENT OF ENERGY YIELD OF PHOTOVOLTIC MODULE
}

\author{
E. Anoliefo ${ }^{1, *}$ and 0. Oparaku ${ }^{2}$

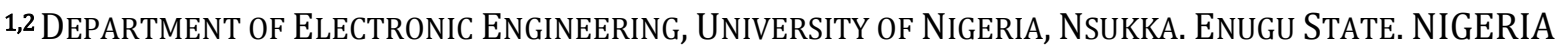 \\ Email addresses.1 edward.anoliefo@unn.edu.ng, 2 ogbonna.oparaku@unn.edu.ng
}

\begin{abstract}
Currently, photvoltaic (PV) modules are characterized based on open circuit voltage, short circuit current as well as voltage and current at maximum power point under strictly specified laboratory conditions. Among manufacturers, regulators and experts, this approach appears reasonably adequate. Nevertheless, among end users and and low level technicians, it may be misleading. This is on account of the critical difference between the laboratory and in situ conditions. This often results to improper design which in turn is capable of accelerating a premature system failure. The present work explores the potentials of natural load variation scheme as a low cost option that is capable of estimating the actual yield of PV modules. Essentially, the scheme consists of a firmware controlling the switching of a number of resistors(loads) connected in parallel. By looping through the resistors in parallel, the firmware matches load impedance to the impedance of the module thus the module operates at its maximum power point. The research results indicate a similar response pattern for constant and variable loads. Nevertheless, the quantitative value of recorded voltage, current, power and energy tended to increase as the number of available resistors incresed. Though clear convergence was not achieved, natural load variation scheme more realistically captures the yield potentials of polycrystalline PV modules under low irradiance conditions.
\end{abstract}

Keywords - impedance matching, energy yield,natural load variation,maximum power point .

\section{INTRODUCTION}

Solar modules produce direct current (DC) electricity. They are usually rated/classified by the power they deliver under specified conditions. Common conditions include: standard test condition (STC) and Photovoltaics for Utility Scale Application (PVUSA) Test Conditions (PTC). Under Standard Test Condition (STC) protocol, solar modules are characterized in a controlled environment where the cell temperature is maintained at $25^{\circ} \mathrm{C}$. With the aid of solar simulator, the irradiance is kept at $1000 \mathrm{~W} / \mathrm{m}^{2}$ while the absolute air mass is kept at 1.5. Under Photovoltaics for Utility Scale Application (PVUSA) Test Conditions (PTC) characterization procedure, the module is kept ten meters above ground while its ambient temperature is maintained at $20^{\circ} \mathrm{C}$. Wind speed of $1 \mathrm{~m} / \mathrm{s}$ and absolute air mass of 1.5 are also kept.

Arguably, these conditions can be recreated in standard laboratories. Unfortunately, solar modules operate under non controlled conditions where various environmental and design factors actually affect the primary purpose of their installation-energy yield [1]. This means that the present rating parameters do not give enough information about the quantity of energy a given PV module will deliver in actual operation when subjected to varying and not easily predictable environmental variables [2].

\section{REVIEW OF RELATED WORKS}

Quite a considerable volume of literature has been devoted to the investigation of the impact of varying environmental conditions as well as in situ design and installation practices on the energy yield of solar modules [3-5]. These efforts have resulted in a number of models which seek to predict the performance of solar module outside standard test conditions. These models often seek to estimate how departure from standard test conditions affect the performance of the module and so make necessary corrections that would give a fair estimate of the modules' outdoor performance.

The single diode model of the solar cell, shown in Figure 1 is one of the most widely adopted models in use [6]. It is based on the equivalent circuit of the solar cell. From the single diode model above, is derived the characteristic equation of solar cell [6]:

$$
I_{l}=I_{R}-I_{o}\left[e^{\frac{q\left(V_{l}+I_{s} R_{s}\right)}{K T}}-1\right]-\frac{V_{l}+I_{l} R_{S}}{R_{s h}}
$$

\footnotetext{
* Corresponding author, tel: $+234-806-363-0992$
} 
From equation (1), it is obvious that junction temperature of the solar cell is a key performance parameter of the solar cell. Since it has inverse relationship with $\mathrm{I}_{\mathrm{L}}$ it imparts negatively on the output current from solar cells. Manufacturers often supply the temperature coefficients of their modules where $\alpha, \beta$ and $\gamma$ represent temperature coefficients of current, voltage and power respectively. Various research findings also indicate that the temperature coefficients also tend to vary with irradiance level [7] [8]. It is important, therefore, to take note of cell temperature while predicting yield of a PV module.

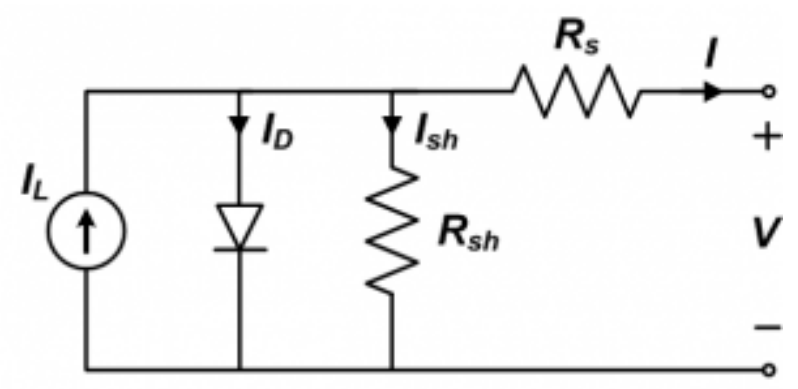

Figure 1: A single diode model of solar cell [6]

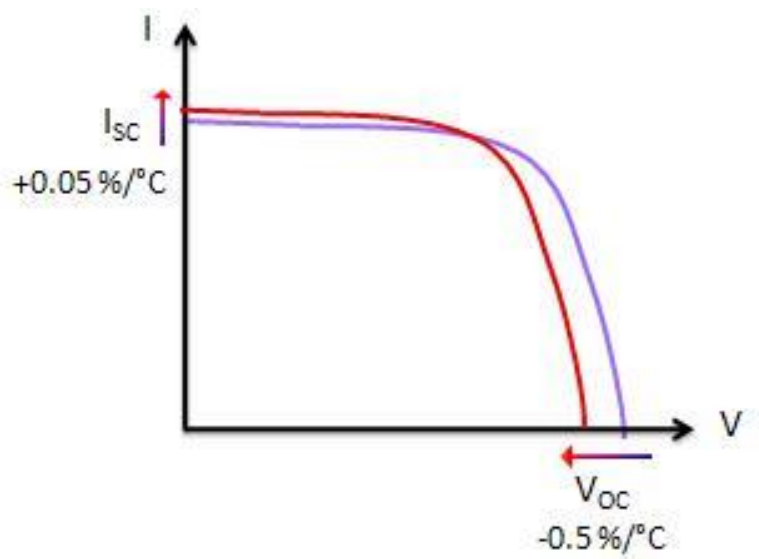

Figure 2: I-V curve showing temperature response of Solar cell [14]

Unfortunately, determination of cell junction temperature is often tedious. To ease the problem, the concept of Nominal Operating Cell Temperature(NOCT) was introduced. It is defined as the temperature reached by open circuited cells in a module when irradiance on cell surface is $800 \mathrm{~W} / \mathrm{m} 2$, at an ambient temperature of $20^{\circ} \mathrm{C}$. The wind velocity is also given as $1 \mathrm{~m} / \mathrm{s}$, while the module is expected to be mounted open back side at an angle of $45^{\circ}$. When the manufacturer gives the NOCT, the equation (2) is used to approximate the cell temperature, given the ambient temperature [9]:

$$
T_{\text {cell }}=T_{\text {air }}+(N O C T-20) \times \frac{E}{80}
$$

In (2) $\mathrm{E}$ is the irradiance at the given time. In applying equation (2), as well as other possible correlations [10] it is important to recognize the limitations imposed by the site specific nature of most of the correlations as already demonstrated by various researchers $[11,12]$.

\subsection{From Standard Test Condition (STC) To Natural Environmental Condition (NEC)}

At present the standard characterizing parameters supplied by PV module manufacturers include: the open circuit voltage $\left(\mathrm{V}_{\mathrm{oc}}\right)$, the short circuit current $\left(\mathrm{I}_{\mathrm{sc}}\right)$, the voltage, current and power at maximum power point $\left(\mathrm{V}_{\mathrm{mpp}}, \mathrm{I}_{\mathrm{mpp}}\right.$ and $\mathrm{P}_{\mathrm{mpp}}$ respectively) under the STC. These parameters, though determined by other manufacturing variables are differently affected by temperature and other environmental variables. Researchers [13] have shown that the following relationship shown in equation (3) exists between $\alpha$ and $I_{s c}$

$$
\mathrm{I}_{\mathrm{sc}(\text { at any other temp })}=\operatorname{Isc}_{(\text {at STC })}(1+\alpha \Delta \mathrm{T})
$$

Similarly, the relationship shown in equation (4) exists between $\beta$ and $V_{O C}$

$$
\mathrm{V}_{\mathrm{OC}} \text { (at any other temp) }=\mathrm{V}_{\mathrm{OC} \text { (at STC) }}(1-\beta \Delta \mathrm{T})
$$

For monocrystalline and polycrystalline both $\alpha$ and $\beta$ have negative coefficients hence while output current increases with temperature, Voc tends to decrease with temperature as shown in Figure 2 . A close look at Figure 2 shows that $0.05 \%$ increase in $\mathrm{I}_{\text {sc }}$ occasioned by temperature is disproportionately cothteracted by the $0.5 \%$ decrease in the Voc. Situations such as this offsets the projected power delivery of $\mathrm{a} 2$ real life PV system. There is ,therefore, a need to translate from STC to Natural Environment Conditions(NEC).

Such translations involve careful study of how environmental variables affect the behavior of an ideal solar cell [15] [6]. They often lead to the development of equations. In the adaptation of these equations it is necessary to understand the specificity of some of the equations [16]. In such situations, site specific relations may be necessary.

\subsection{Energy Yield as a Characterizing Parameter}

Though at present, solar PV modules are generally rated in terms of Voc, Isc, Vmp, Imp and Pmax, researchers are seeking other [17]. One of such methods is the use of energy yield as elucidated by the National Renewable Energy Laboratory(NREL) USA .NREL has shown that it is possible to find a concensus among various energy yield procedures under outdoor conditions and have developed energy yield calculators based on equation (5) [18] [19]):

$$
\mathrm{E}=\mathrm{A} \times \mathrm{r} \times \mathrm{H} \times \mathrm{PR}
$$

In (5), E is the Energy (kWh), A is the Total solar panel Area $\left(\mathrm{m}^{2}\right), \mathrm{r}$ is the solar panel yield given by the ratio of 
maximum power in $\mathrm{kW}$ to the area in $\mathrm{m}^{2}, \mathrm{H}$ is the annual average solar radiation on tilted panels (shadings not included) and PR is the performance ratio, coefficient for losses (range between 0.5 and 0.9 , default value $=0.75$ ) The problem with this procedure is that it depends on a yearly average which may not reflect ever changing weather variables. Researchers have also attempted a physical model for estimation of daily Energy yield by using equation (6) [20] .

$$
\begin{aligned}
E=\sum_{t=0}^{24} P_{s t c} \times\{G & \left.(t) \times \frac{t}{1000}\right\} \\
& \times\left\{1+\% \frac{\gamma_{P m p}}{100}(T(t)-25)\right\} \times \text { fdirt } \\
& \times f m m \times \text { fcable } \times \text { finv }
\end{aligned}
$$

Where: $\mathrm{F}_{\text {dirt }}=$ correction factor in respect of dirt,

$\mathrm{F}_{\mathrm{mm}}=$ correction factor in respect of mismatch

$\mathrm{F}_{\text {cable }}=$ correction factor in respect of cable losses

$\mathrm{F}_{\text {inv }}=$ correction factor in respect of inverter

$\gamma_{P m p}$ Temperature coefficient for $\mathrm{P}_{\mathrm{mp}}\left(\% /{ }^{\circ} \mathrm{C}\right)$

Here there still exists the issue of STC rating, though standard translation procedures were introduced. Again average irradiance is replaced with sampled irradiance which represents some improvement but sampling time is yet high since instantaneous irradiance tend to change in seconds. Researchers [21] have also reviewed the use of Artificial Neural Method in the estimation of energy yield of solar PV and reported a successful fusion of physical and artificial neural methods in their work.

The International Electrotechnical Commission (IEC) developed energy rating standard IEC 61853 [22]. It provides guidelines on energy rating by calculating the energy yield on the basis of PV module characteristics and parameters, including irradiance, temperature, incident angle and spectral distribution. The calculations are performed using either given standard days or sitespecific measured data. In the evaluation of site-specific data, the effort required of measurement equipment is enormous. In particular, the direct beam radiation Gdir and the solar spectrum $E(\lambda)$ have to be measured among many other parameters [23].

\subsection{The Load Variation Approach}

A clear conclusion arising from the review of several works already cited is that the yield of solar modules is affected by so many factors some of which are site specific. Earlier works have sought to characterize and factor in these variables in an effort to make fairly accurate global projection on the yield of solar modules. While these efforts may be quite useful to experts imbued with sophisticated measuring instrument, they do not sufficiently equip the low end technicians and owners of PV modules with a fairly simple method of determining the energy yield potentials of their module. Existing characterization of PV module often capture performance at maximum power point. The standard characterization procedure often involve expensive laboratories and complex measuring instruments. Accordingly, researchers in the less developed world often resort to using single resistive load to study the dynamic response of PV module to irradiance and other environmental variables. This can lead to a misreading of the power and yield of a given PV module. This erroneous methodology has led researchers to arrive at misleading conclusions such as [24] which indicated the non viability of PV modules as a serious source of power in south eastern Nigeria. The natural load variation scheme being proposed is, simply put, an impedance matching algorithm that dynamically seeks to match load impedance to the dynamic impedance developed along the IV curve of the PV module in response to changes in irradiance and other significant environmental variables. The basic goal is to get the module to operate around its maximum power point. As evident from the nature of the flowchart, shown in Figure 3, the process is an endless loop. It continues until it is forcefully stopped. At start up, an Arduino based firmware gradually switch an $\mathrm{N}$ array of resistors arranged in parallel from $R=1$ to $R=N$ (thus changing the effective value of the total resistance seen). At each instance, the voltage, current and power are read out and stored by the microcontroller. The firmware contains a sub routine which loops through all the calculated power for different values of current and voltage as different numbers of resistors are switched on. The minimum calculated power calculated in the course of loop becomes Pmin. The maximum value becomes the Pmax. Pmax is subsequently chosen as the reference. Meanwhile the microcontroller keeps reading the voltage and current at the maximum power point. The power gotten at this point is described as the instantaneous power (Pinst). The moment the instantaneous power records a $10 \%$ deviation from the chosen maximum power point, the system automatically finds the new $\mathrm{N}$ number of resistors that would ensure maximum power transfer from the panel.

\section{METHODOLOGY}

For the purpose of demonstrating the effect of varying the number of resistors in the natural load variation scheme, an experiment was conducted using Arduino mega (a microcontroller),three 30W PV modules, a number of choke resistors and TIP 31. The set up is shown in Figure 4. 


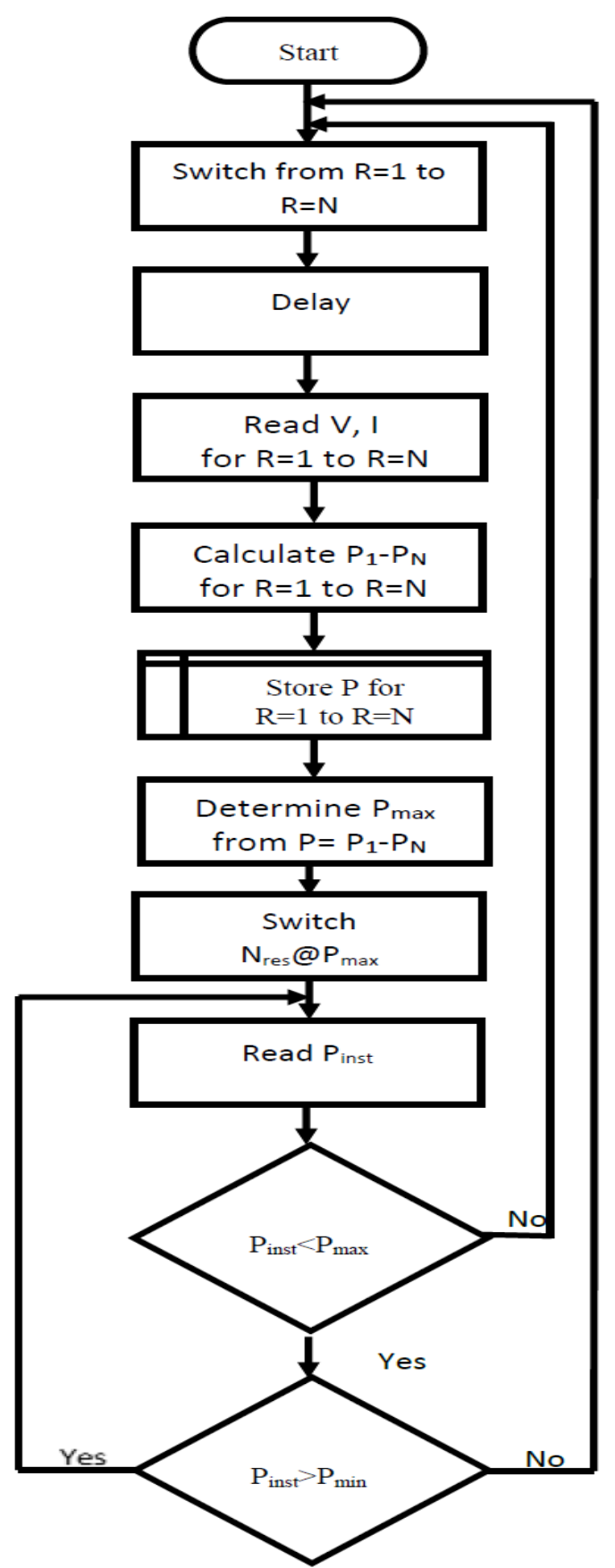

Figure 3: Process flowchart for switching load

Prior to the experiment, the optimal load resistance of the modules, at rated maximum power point, was determined from the rated current and voltage at maximum power point using Ohm's law- $\mathrm{R}=\mathrm{V} / \mathrm{I}$.

The current at maximum power point is given as $1.71 \mathrm{~A}$ while the voltage at maximum power point is given as $17.5 \mathrm{~V}$, hence load resistance at rated maximum power point is calculated to be $10.23 \Omega$ ). This serves as the low end optimal resistance ie the dynamic module resistance when an irradiance of $1000 \mathrm{~W} / \mathrm{m}^{2}$ falls on the module when the cell temperature is $25^{\circ} \mathrm{C}$. The high end would ideally exist during open circuit when $\mathrm{R}$ is infinite

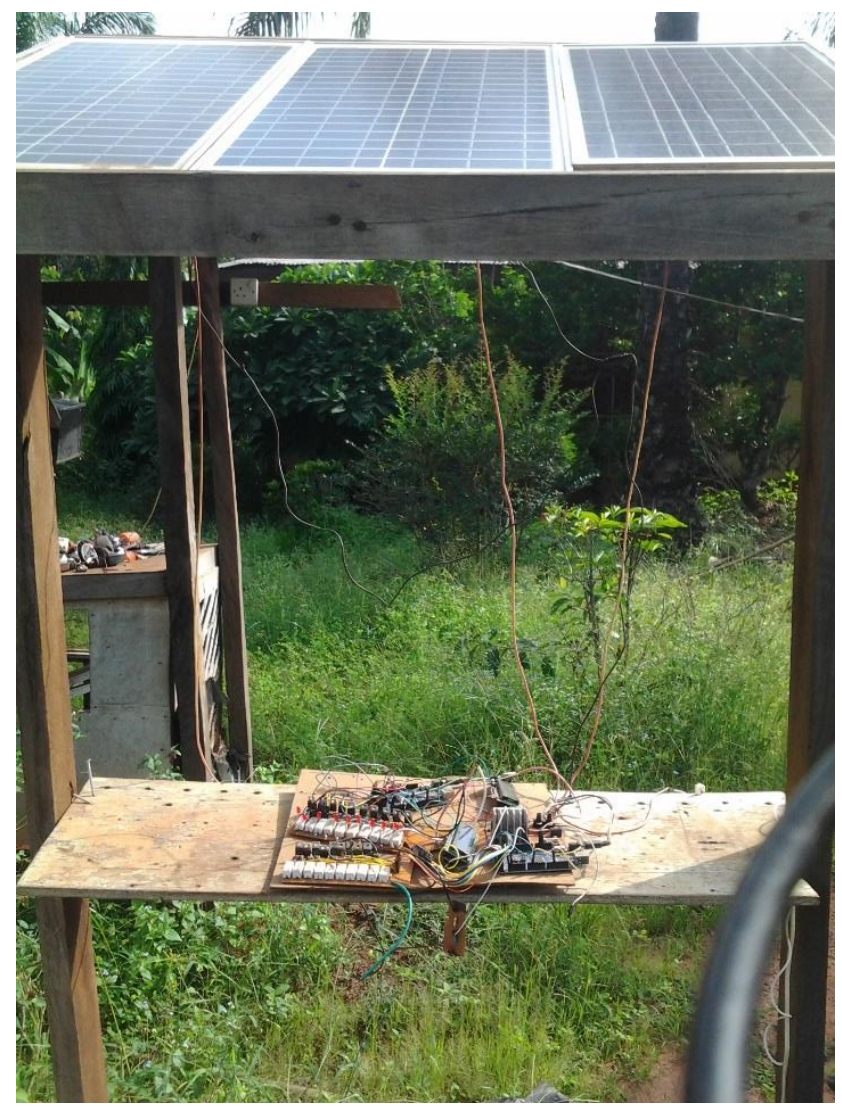

Figure 4: The experimental set up

. Practically, however, in view of rating and use of the module under consideration, it is convenient to assume that the when the output current from the module is $0.1 \Omega$, the output voltage is virtually equal to the rated open circuit voltage $22.5 \mathrm{~V}$. Accordingly the dynamic module resistance at the point would, in accordance with Ohm's law, be $225 \Omega$. The optimal number(N) of resistors should be such as would allow a natural variation between $225 \Omega$ and $10.3 \Omega$.

To achieve this, a number of parallel resistors needed to be placed in parallel so that as the need arises an $\mathrm{N}$ number of resistors would be switched. To find a general a reference was made to the traditionally formula for calculating the equivalent resistance of resistors in parallel. Assuming a case of four resistors in parallel

$$
\frac{1}{R_{e q}}=\frac{1}{R_{1}}+\frac{1}{R_{2}}+\frac{1}{R_{3}}+\frac{1}{R_{4}}
$$

This can be rearranged such that

$$
\frac{1}{R_{e q}}=\frac{R_{2} R_{3} R_{4}+R_{1} R_{3} R_{4}+R_{1} R_{2} R_{4}+R_{1} R_{2} R_{3}}{R_{1} R_{2} R_{3} R_{4}}
$$

This is also equivalent

$$
\text { Req }=\frac{R_{1} R_{2} R_{3} R_{4}}{R_{2} R_{3} R_{4}+R_{1} R_{3} R_{4}+R_{1} R_{2} R_{4}+R_{1} R_{2} R_{3}}
$$

If $R_{1}=R_{2}=R={ }_{3}=R_{4}$ equation 8 could easily transform into

$$
R e q=\frac{R^{4}}{R^{3}+R^{3}+R^{3}+R^{3}}
$$


Generalized, equation (9), could easily become

$$
R e q=\frac{R^{N}}{N R^{(N-1)}}
$$

It can also be further simplified into:

$$
\operatorname{Req}=\frac{R}{N}
$$

Applying the low end and high end and high end optima to equation 12

$$
N=\frac{R e q}{R}
$$

Plugging into the equation, optimal $N=\frac{225}{10.3} \approx 22$.

To determine the power rating of the individual resistors used, it was noted that following simple application of Ohm's law, maximum current will flow when the entire $\mathrm{N}$ resistors in parallel are on. For the purposes of simplification, it was necessary to assume that all the resistances were in fact identical and that current was evenly shared among them. The maximum current roughly corresponds to the maximum rated current the given module would deliver. The minimum power ratings of the individual resistors were determined theoretically using the following relations:

$$
P_{\text {diss }}=I_{\max }^{2} \times R
$$

In (14), $I_{\max }=I_{m p} / N$. The calculated results are shown in Table 1. Since the calculated power represents the minimum, higher values were used for the experiment as also shown in Table 1.

Table 1: List of resistors used

\begin{tabular}{lllll}
\hline $\mathrm{N}$ & $\mathrm{R}_{\text {calculated }}$ & $\mathrm{R}_{\text {available }}$ & $\mathrm{P}_{\text {calculated }}$ & $\mathrm{P}_{\text {used }}$ \\
\hline 1 & $10.3 \Omega$ & $10 \Omega$ & $30.625 \mathrm{~W}$ & $40 \mathrm{~W}$ \\
4 & $40 \Omega$ & $39 \Omega$ & $7.31 \mathrm{~W}$ & $10 \mathrm{~W}$ \\
12 & $120 \Omega$ & $120 \Omega$ & $2.4 \mathrm{~W}$ & $5 \mathrm{~W}$ \\
22 & $220 \Omega$ & $220 \Omega$ & $1.33 \mathrm{~W}$ & $5 \mathrm{~W}$ \\
27 & $270 \Omega$ & $270 \Omega$ & $1.08 \mathrm{~W}$ & $5 \mathrm{~W}$ \\
\hline
\end{tabular}

To provide the natural load variation, a certain number (N) of resistors were placed in parallel. An Arduino based firmware was developed. The development of the firmware was modularized. At start up, the check_Mpower function is called up to switch different number of resistors by looping from $\mathrm{R}=1$ to $\mathrm{R}=\mathrm{N}$. It then chooses an $\mathrm{R}$ value that delivers the maximum power for a given irradiance, temperature and other relevant variables. The turn_on_load function switches the appropriate number of resistors. This process is repeated whenever there is a $10 \%$ variation in recorded power. To achieve this, check_Instpower function regularly monitors instantaneous power generated as a result of variations in weather condition.

A datalogging function was also developed. Two files were created and regularly updated after every two minutes. One file recorded the switching behavior while the other one recorded voltage, current, power and yield. In either case, common statistical methods were used to generate mean and standard deviation.

\subsection{Measurements And Error Analysis}

A simple voltage divider rule was applied for voltage measurement. To meet the requirement for high input impedance in voltage measurement, $1 \mathrm{M} \Omega$ and $10 \mathrm{M} \Omega$ resistors were used to form the voltage divider. This enables a voltage of up to $40 \mathrm{~V}$ to be safely measured on a $5 \mathrm{~V}$ microcontroller. The rated tolerance of the resistor was $10 \%$. To compensate for this, the multiplication factor was individually determined by calibration against Fluke 117 true rms multimeter. The analogRead() of the Arduino microcontroller can introduce random error of up to $5 \%$. To reduce this error, a function that performed statistical analysis was introduced. The mean of fifty readings was used for energy calculation and the standard deviation of the readings recorded. An extraordinarily high standard deviation was regarded as indicative of serious error hence such readings were discarded.

\subsection{Energy Yield Calculation}

To calculate the energy yield of a given PV module, the current and voltage measurement procedure described above were used to generate voltage and current values which were multiplied to generate power. On account of the constantly changing values of voltage and current, the energy yield at a given time was calculated by multiplying power by the elapsed time. A process of continuous addition was then used to determine the total energy yield.

\section{RESULT AND DISCUSSION}

Under a sustained low irradiance level, systems with $\mathrm{N}>1$ progressively tended to generate comparatively higher power as shown in figure 7. Under a sustained high irradiance level, the systems tended to perform equally except for slight variations attributable to differences in the value of total resistance as seen by the system. Resistances slightly lower than the calculated resistance at the rated maximum power point tended to generate higher power. Under situations of high swing in irradiance values, the system with $\mathrm{N}=4$ tended to respond faster and attain stability and was better at making an optimal choice of $\mathrm{N}$. The system with $\mathrm{N}=15$ took longer time to settle under such situations. The result is often wrong choice of optimal $\mathrm{N}$ which empirical evidence show negatively affected the power generated. This is because accurate choice of $\mathrm{N}$ was necessary for current calculation of current. 


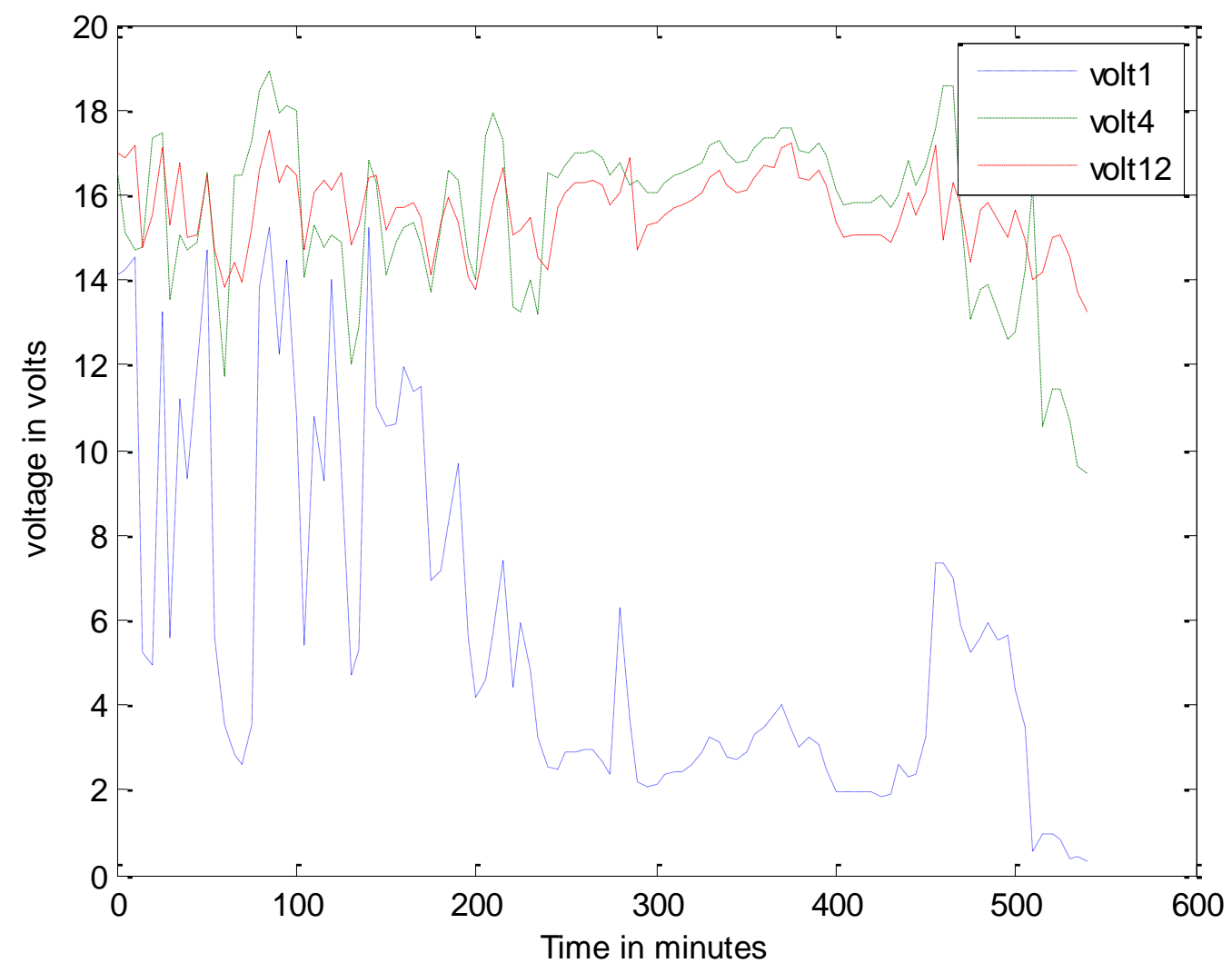

Figure 5: Graph of voltage against time

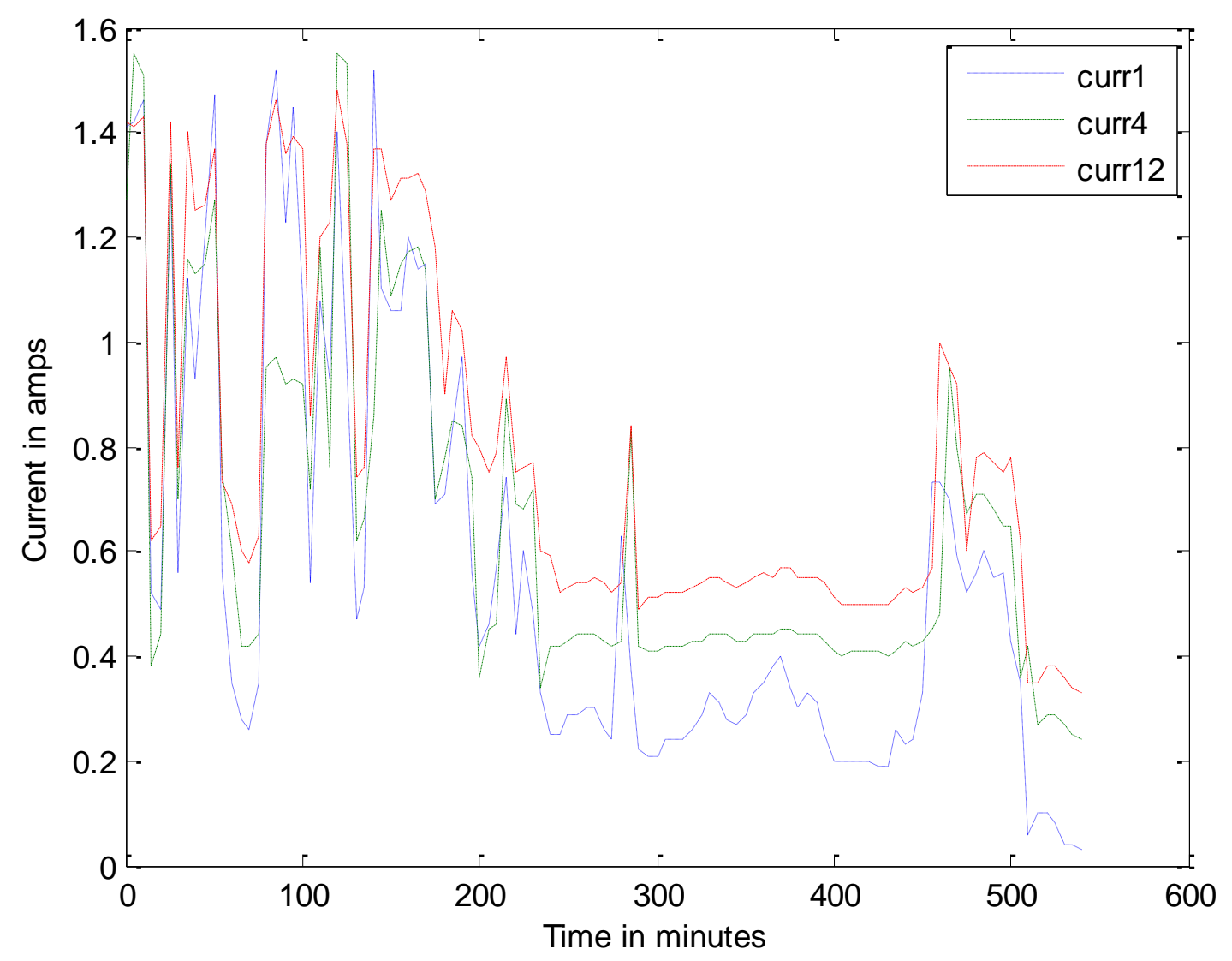

Figure 6: Graph of current against time 


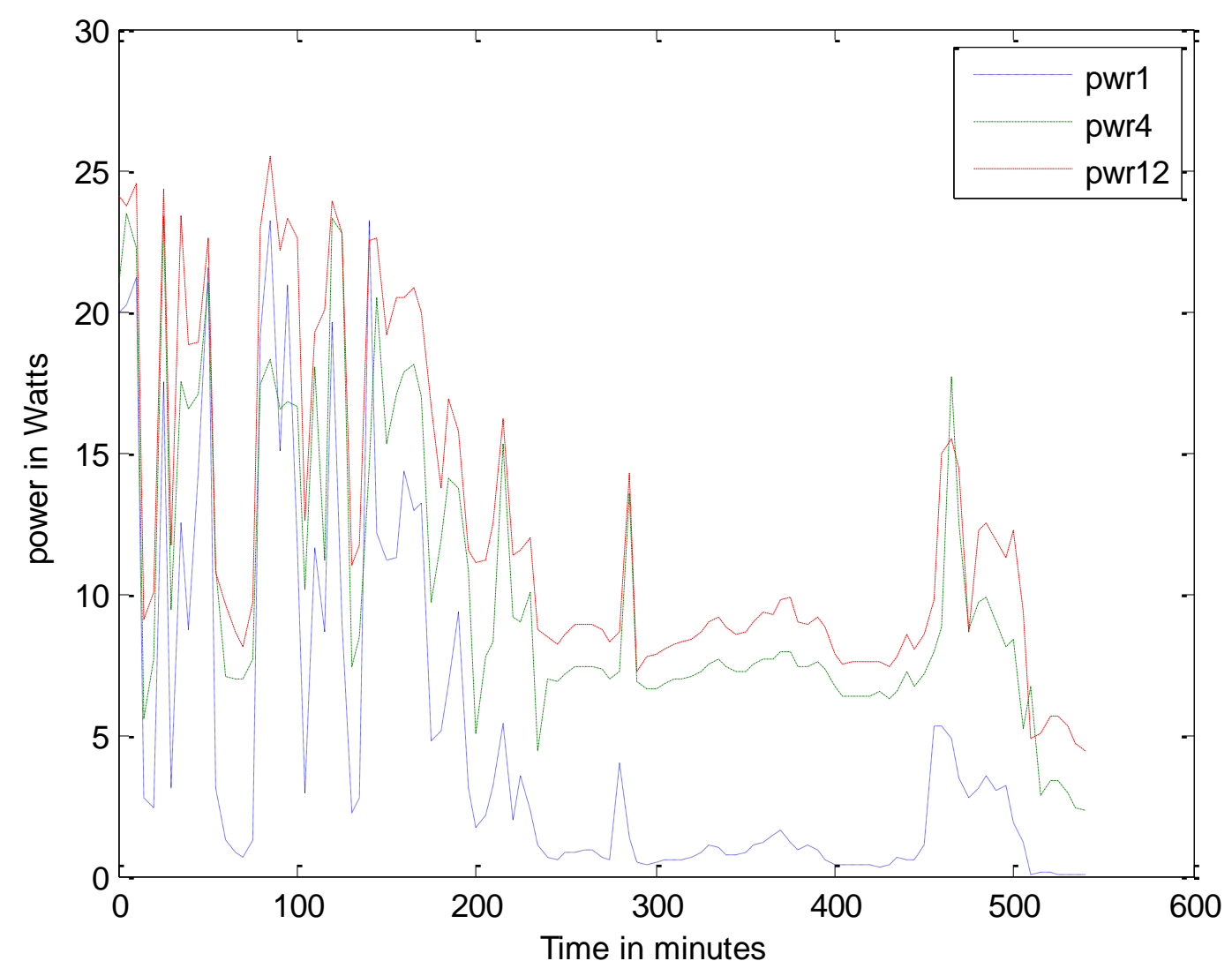

Figure 7: Graph of power against time

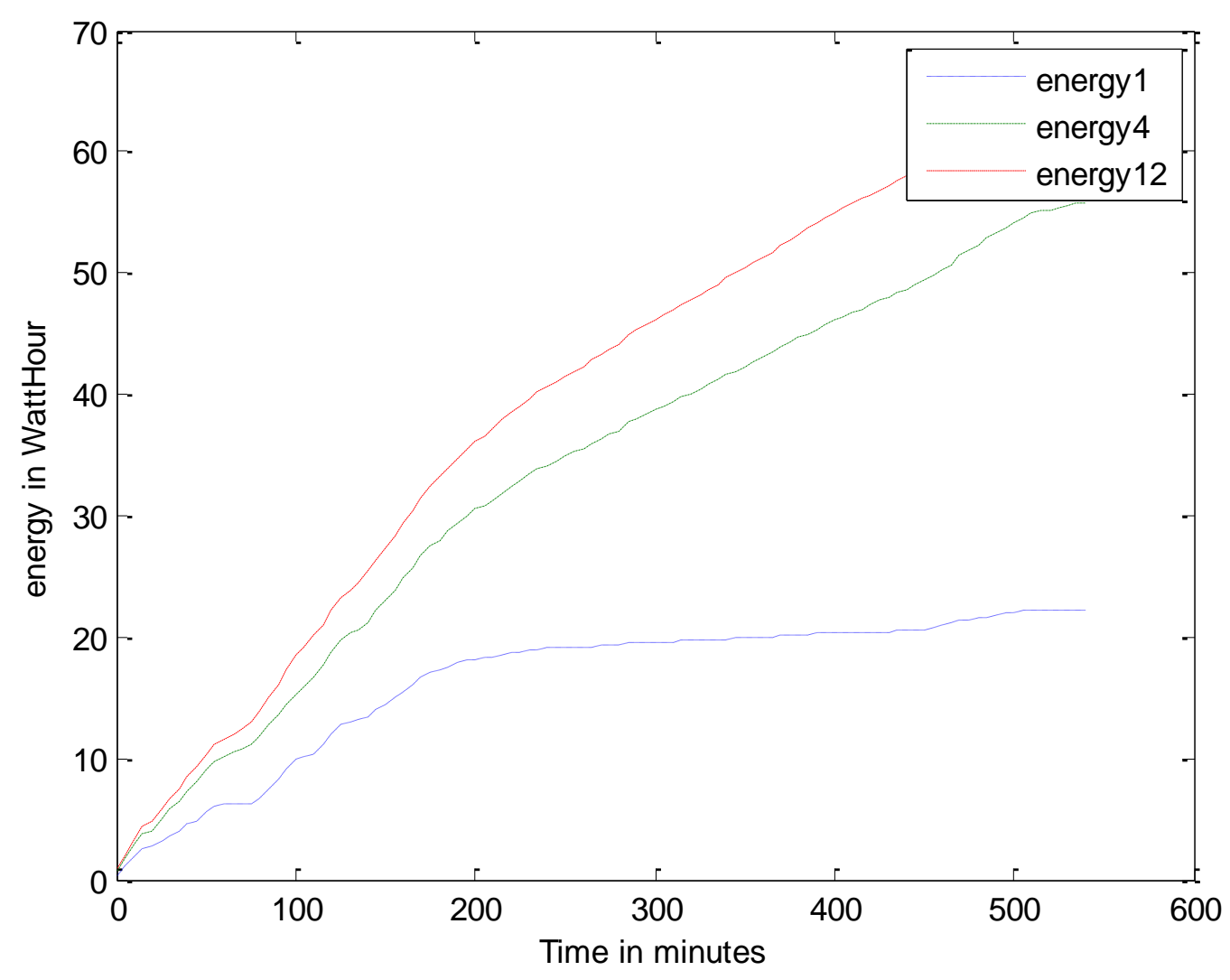

Figure 8: Graph of energy against time 
This finding is in agreement with recent research findings [25 - 28] on dependence of shunt and series resistance on irradiance at low irradiance levels. The authors demonstrate that at low irradiance shunt resistance tended to increase with decrease in irradiance while series resistance tended to decrease with decrease in irradiance. The curve is shown to be an inverse of $\mathrm{I}-\mathrm{V}$ curve. Hence series resistance can be roughly determined by calculating the inverse of the slope of the I-V curve at the open circuit voltage and the shunt resistance from the inverse of the slope of the I-V curve at the short circuit condition $\mathrm{V}=0$. Maroor Ahmed [29] in his analysis based on the five parameter single diode showed that while the fill factor varied inversely with series resistance, its relationship with shunt resistance is an inverse of the characteristic I-V curve.

\section{CONCLUSIONS}

The load variation approach provided better way of studying the outdoor performance of a PV module. This is because it provides a dynamic impedance matching between load and PV in the course of the dynamic interplay of the various environmental and design factors that are known to affect the yield of the PV module. As the number of $\mathrm{N}$ increased, there was the graph power against time tended to converge. Final convergence was not recorded. Hence the system may not, on its own, provide an absolutely correct measure of energy yield. A study is ongoing to discover a correcting equation that would enable an absolutely correct measurement when $\mathrm{R}$ number of resistors is used. Meanwhile, natural load approach would enable outdoor measurement of PV module under any environmental condition. The observed limitation on its usefulness in absolute measurement of energy yield may be compensated via a comparative approach. Under this approach, the yield of a properly characterized module may be compared to that of another module whose characterization status is questionable. In this way the advantage of load variation approach would be used while its shortfall would be avoided.

\section{ACKNOWLEDGEMENT}

The authors wish to acknowledge the contribution of Chinedu Mama and Chrisantus Obinna Nnamani in the course of experiment and documentation of this work.

\section{REFERENCES}

[1] Endecon Engineering, "A Guide TO Photovoltaic (PV) System Design and Installation," California Energy Commission Energy Technology Development Division, California, 2001.
[2] Bucher K., "Leading to a true module rating of energy and power by analysis of module power loss mechanisms.," Proceedings os the 13th European Photovoltaic Solar Energy Conference, pp. 20972103, 1995.

[3] Arash Sayyah and Mark, N, "Energy yield loss caused by deposition on photovoltaic panels," Solar Energy, no. 107, pp. 576-604, 2014.

[4] Mekhilef S. Saidur Rahman, Kamalisarvestani.M. , "Effect of dust humidity and air velocity on efficiency of photovoltaic cells," Renewable and sustainable energy reviews, no. 16, pp. 2920-2925, 2012.

[5] Bing Guo , Javed W, Figgis B.W, "Effects of dust and weather conditions on photovoltaic performance in Doha, Qatar," in Smart Grid and Renewable Energy (SGRE), Doha Qatar, March 2015.

[6] Green M.A. , Solar Cells, New Jersey: Englewood Cliffs, 1982.

[7] Dash P .K, and N C Gupta, "Variation of Temperature Coefficient of Different Technology Photovoltaic Modules with respect to Irradiance," International Journal of Current Engineering and Technology, vol. 5, no. 1, p. $2347-5161,2015$.

[8] Virtuani A. Pavanello.D, Friesen. G, "overview of temperature coefficients of different thin film photovoltaic technologies," in 5th World Conference on Photovoltaic Energy Conversion, Valencia, Spain, 2010.

[9] Garcia, M. C. A. "Estimation ofphotovoltaic module yearly temperature and performance based on Nominal Operation Cell Temperature calculations," Renewable Energy 29 , vol. 29, pp. 1997-2010, 2004.

[10] Skoplaki, E. Palyvos J.A., “Operating temperature of photovoltaic modules:A survey of pertinent correlations," Renewable Energy, vol. 34, p. 23-29, 2009.

[11] Mondol, Jayanta Deb, Yohanis, Yigsaw , Norton, "Comparison of measured and predicted long term performance of grid a connected photovoltaic system," Energy Conversion and Management, vol. 48, no. 4, pp. 1065-1080, 2006.

[12] Ugwuoke, P.E., Ezema, F.I. and Okeke, C.E., "Performance Assessment of Polycrystalline Silicon PV Modules in Low Latitude Region as A Function of Temperature," International Journal of Applied Science and Technology, vol. 2, no. 3, pp. 295-301, 2012.

[13] Nnadi D.B.N, “Environmental/Climatic Effect On Stand-Alone Solar Energy Supply Performance For Sustainable Energy," Nigerian Journal of Technology, vol. 31, no. 1, pp. 79-88., 2012. 
[14] "Photovoltaic Cell I-V Characterization Theory and LabVIEW Analysis Code," National Instruments, 10 $52012 . \quad$ [Online]. Available: http://www.ni.com/white-paper/7230/en/.

[Accessed 12 December 2016].

[15] Gow J.A. , Manning C.D., "Development of a photovoltaic array model for use in power electronics simulation studies," IEEE Proc.-Electr. Power Applications, vol. 146, no. 2, p. 193, 1999.

[16] Marko Topič, Kristijan Brecl, Jurij Kurnik, and James Sites, "Effective Efficiency And Performance Ratio As Energy Rating System For Pv Modules," in 21st European Photovoltaic Solar Energy Conference, Dresden, Germany, 4-8 September 2006, .

[17] KennyR. P., “A practical method for the energy rating of $\mathrm{c}-\mathrm{Si}$ photovoltaic modules based on standard tests," Progress In Photovoltaics: Research And Applications, vol. 14, p. 155-166, 2006.

[18] Kroposki B. and Marion W., "Comparison of Module Performance Characterization Methods for Energy Production," National Renewable Energy Laboratories, Colorado, 2000.

[19] Aron P. Dobos, "PV Watts Version 5 Manual," Nrel, Springfield, VA 22161, 2014.

[20] Omar A. M. Hussin,M. Z, Shaaria S. , Sopianb.K. , "Energy Yield Calculation of the Grid Connected Photovoltaic Power System," Computer Applications in Environmental Sciences and Renewable Energy, vol. 14, pp. 162-167, 2014.

[21] Giorgio Graditi et al, "Energy yield estimation of thin-film photovoltaic plants by using physical approach and artificial neural networks," Solar Energy, vol. 130, pp. 232-243, 2016.

[22] Govindasamy Tamizh Mani et al, "Photovoltaic Module Power Rating Per Iec 61853-1 Standard :A Study Under Natural Sunlight.," Solar America Board for Codes nand Standards, Arizona, 2011.
[23] Govindasamy TamizhMani, Karen Paghasian, Joseph Kuitche, Meena Gupta Vemula, "Photovoltaic Module Power Rating per IEC 61853-1Standard: A Study Under Natural Sunlight," Arizona State University, Arizona, 2011.

[24] Ogueke N.V., Fidelis Abam, Kevin N. Nwaigwe, Anyanwu.E. E., "The Effect Of Seasonal Variation and Angle of Inclination on the Performance of Photovoltaic Panels in South Eastern Nigeria.," Research Journal of Applied Sciences, Engineering and Technology, vol. 5, no. 3, pp. 794-800, 2013.

[25] Kandil M. Kandil et, "Investigation of the Performance of CIS Photovoltaic Modules under Different Environmental Conditions," Smart Grid and Renewable Energy, vol. 1, no. 2, pp. 375-387, 2011.

[26] Nazrul Islam, Rahman M.Z, Monimussaman S.M, "The Effect of Irradiation on Different Parameters of Monocrystalline Photovoltaic Solar Cell," in 3rd International Conference on the Developments in Renewable Energy Technology (ICDRET), Dhaka, Bangladesh, 2014.

[27] C. Ruschel, "Assessment of PV module shunt resistance dependence on solar irradiance," Science Direct, vol. 133, pp. 35-43, 2016.

[28] Grunow ,P. Lust S. Sauter D, Podlowski. L, “Weak Light Performance And Annual Yields Of Pv Modules And Systems As A Result Of The Basic Parameter Set of Industrial Solar Cells," in 19th European Photovoltaic Solar Energy Conference, Paris, France, 200.

[29] M. Ahmed, "PV-Cells Series Shunt Resistance," 20 June 2012. [Online]. Available: https://www.scribd.com/document/97666562/10MS-LECTURE-PV-CellsSeriesShuntResis. [Accessed 5 March 2017]. 